\title{
Intracranial Atherosclerotic Burden on 7T MRI Is Associated with Markers of Extracranial Atherosclerosis: The SMART- MR Study
}

\author{
(D) M.H.T. Zwartbol, (D) M.I. Geerlings, (D) R. Ghaznawi, (D). Hendrikse, and (D)A.G. van der Kolk,
} on behalf of the UCC-SMART Study Group

i

\begin{abstract}
BACKGROUND AND PURPOSE: Intracranial atherosclerosis, a major risk factor for ischemic stroke, is thought to have different atherogenic mechanisms than extracranial atherosclerosis. Studies investigating their relationship in vivo are sparse and report inconsistent results. We studied the relationship between intracranial atherosclerosis and extracranial atherosclerosis in a cohort of patients with a history of vascular disease.
\end{abstract}

MATERIALS AND METHODS: Within the Second Manifestations of ARTerial disease-Magnetic Resonance (SMART) study, cross-sectional analyses were performed in 130 patients (mean age, $68 \pm 9$ years) with a history of vascular disease and with assessable 7T intracranial vessel wall MR imaging data. Intracranial atherosclerosis burden was defined as the number of intracranial vessel wall lesions in the circle of Willis and its major branches. Age- and sex-adjusted unstandardized regression coefficients (b-value) were calculated with intracranial atherosclerosis burden as the dependent variable and extracranial atherosclerosis markers as independent variables.

RESULTS: Ninety-six percent of patients had $\geq 1$ vessel wall lesion, with a mean intracranial atherosclerosis burden of $8.5 \pm 5.7$ lesions. Significant associations were observed between higher intracranial atherosclerosis burden and carotid intima-media thickness $(b=0.53$ lesions per $+0.1 \mathrm{~mm} ; 95 \% \mathrm{Cl}, 0.1-1.0$ lesions), $50 \%-100 \%$ carotid stenosis versus no stenosis $(b=6.6$ lesions; $95 \% \mathrm{Cl}$, 2.3-10.9 lesions), ankle-brachial index $\leq 0.9$ versus $>0.9$ ( $b=4.9$ lesions; $95 \% \mathrm{Cl}$, 1.7-8.0 lesions), and estimated glomerular filtration rate $(b=-0.77$ lesions per $+10 \mathrm{~mL} / \mathrm{min} ; 95 \% \mathrm{Cl},-1.50$ to -0.03 lesions). No significant differences in intracranial atherosclerosis burden were found among different categories of vascular disease.

CONCLUSIONS: Intracranial atherosclerosis was associated with various extracranial markers of atherosclerosis, not supporting a different etiology.

ABBREVIATIONS: $\mathrm{ABI}=$ ankle-brachial index; $\mathrm{CIMT}=$ carotid intima-media thickness; ECAS $=$ extracranial atherosclerosis; eGFR $=$ estimated glomerular filtration rate; ICAS $=$ intracranial atherosclerosis

ntracranial atherosclerosis (ICAS) is a major cause of adverse cerebrovascular events such as ischemic stroke. ${ }^{1}$ Furthermore,

Received July 27, 2019; accepted after revision September 24.

From the Department of Radiology (M.H.T.Z., R.G., J.H., A.G.v.d.K.) and Julius Center for Health Sciences and Primary Care (M.I.G., R.G.), University Medical Center Utrecht and Utrecht University, Utrecht, the Netherlands.

Jeroen Hendrikse has received funding from the European Research Council under the European Union's Horizon 2020 Program (H2020)/European Research Council grant agreement No. 637024 (HEARTOFSTROKE) and H2020 grant agreement No. 666881, SVDs@target, and is supported by the Netherlands Organization for Scientific Research under grant No. 91712322.

Please address correspondence to Mirjam I. Geerlings, PhD, University Medical Center Utrecht, Julius Center for Health Sciences and Primary Care, PO Box 85500 Stratenum 6.131, 3508 GA Utrecht, the Netherlands; e-mail:

m.geerlings@umcutrecht.nl

-- Indicates open access to non-subscribers at www.ajnr.org

E Indicates article with supplemental on-line tables.

Indicates article with supplemental on-line photo.

http://dx.doi.org/10.3174/ajnr.A6308 it is associated with an increased risk of cognitive decline and dementia. ${ }^{2}$ A wide range of prevalence estimates for ICAS has been reported, ranging from $4 \%-51 \%$ in asymptomatic populations to $43 \%-70 \%$ in patients with ischemic stroke. ${ }^{3,4}$

ICAS is currently seen as the intracranial phenotype of atherosclerosis, a generalized disease that can affect all large arteries. Nonetheless, correlations between intracranial and extracranial atherosclerotic disease in postmortem studies are modest. ${ }^{5}$ Furthermore, ICAS has a later time of onset, slower rate of progression, and different plaque morphology compared with other arterial territories. ${ }^{6-8}$ As a result, it has been suggested that ICAS might have a different etiology than extracranial disease. Studies investigating the relationship between intracranial and extracranial disease in vivo are sparse and often limited to one extracranial vessel bed. Furthermore, all of these studies have used lumenographic imaging methods, which can assess only luminal stenosis. ${ }^{9,10}$ Therefore, intracranial plaques without stenosis (ie, 
due to arterial remodeling) will not be detected, leading to an underestimation of the actual ICAS burden. ${ }^{11}$

Vessel wall lesions are a novel neuroimaging marker of ICAS, which can be assessed using intracranial vessel wall MR imaging. ${ }^{12}$ Vessel wall MR imaging enables visualization of the intracranial arterial walls, allowing a more direct evaluation of ICAS. ${ }^{13}$ Currently, 7T is the highest field strength at which vessel wall MR imaging has been performed in humans in vivo and has been shown to be superior to lower field strengths in the detection of vessel wall anomalies. ${ }^{14}$

In the current study, we investigated, in patients with atherosclerotic disease, to what extent markers of extracranial atherosclerosis (ECAS) were associated with the burden of ICAS measured by $7 \mathrm{~T}$ vessel wall $\mathrm{MR}$ imaging, thereby providing insight into the etiology of ICAS and its relationship with ECAS.

\section{MATERIALS AND METHODS Study Sample}

Data were used from the Second Manifestations of ARTerial disease-Magnetic Resonance (SMART-MR) study, a prospective cohort study at our institution with the aim of investigating risk factors and clinical outcomes of MR neuroimaging markers in patients with arterial disease. ${ }^{15}$ In brief, from 2001 through 2005, thirteen hundred nine patients newly referred to our institution with cerebrovascular disease, peripheral arterial disease, coronary artery disease, or abdominal aortic aneurysm without MR imaging contraindications were enrolled in the SMART-MR study. On a 1-day visit to our institution's hospital, the participants underwent 1.5T MR imaging of the brain, a physical examination, ankle-brachial index (ABI) assessment, ultrasonography of the carotid arteries, blood and urine sampling, and questionnaires to assess risk factors, medical history, and daily functioning. Follow-up examinations of the SMART-MR cohort were performed in 2006-2009 and 2013-2017.

From June 2016 to October 2017, we included 147 patients participating in the second follow-up examination of the SMART-MR study who had intracranial vessel wall MR imaging performed as part of a 7T MR imaging of the brain. ${ }^{12}$ A flowchart of the study sample is provided in the On-line Figure. Seventeen patients were excluded from the current study because of artifacts hampering vessel wall MR imaging assessment of $\geq 1$ major segment of the circle of Willis (major segments included the distal internal carotid artery and primary branches [M1, A1, P1] of the anterior, middle, and posterior cerebral arteries), leaving 130 patients for the final analysis. For the current study, measurements of extracranial atherosclerosis and risk factor assessment, including questionnaire data and blood and urine sampling, were obtained (median, 2.3 years; range, $0.6-8.6$ years) before the $7 \mathrm{~T}$ MR imaging.

Comparison of ECAS markers between the excluded patients and the patients for final analysis showed a higher prevalence of $50 \%-100 \%$ carotid stenosis in the excluded patients (7.0\% versus $23.5 \% ; P=.04, \chi^{2}$ test). Also, the excluded patients were older, though this feature was not statistically significant (70 \pm 7 versus $68 \pm 9$ years; $P=.11$, Student $t$ test). Sex distribution did not differ between included and excluded patients (88\% versus $88 \%$ men; $P=.95, \chi^{2}$ test).

\section{Vascular Risk Factors}

Information on general vascular risk factors was obtained by questionnaires, physical examination, and blood sampling. Height and weight were used to calculate the body mass index (kilogram/square meter). Systolic blood pressure (millimeter of mercury) and diastolic blood pressure (millimeter of mercury) were measured by averaging 3 separate measurements with a sphygmomanometer. Hypertension was defined as a systolic blood pressure of $>140 \mathrm{~mm} \mathrm{Hg}$, a mean diastolic blood pressure of $>90 \mathrm{~mm} \mathrm{Hg}$, or self-reported use of antihypertensive drugs. Diabetes mellitus was defined as fasting serum glucose levels of $\geq 7.0 \mathrm{mmol} / \mathrm{L}$ and/or use of glucose-lowering medication and/or a known history of diabetes. Patients who did not meet these criteria, but with a fasting plasma glucose level $\geq 7.0 \mathrm{mmol} / \mathrm{L}$ at baseline, were considered to have diabetes at baseline if they received treatment with glucose-lowering medication within 1 year after baseline. Hyperlipidemia was defined as a total cholesterol of $>5.0 \mathrm{mmol} / \mathrm{L}$, a low-density lipoprotein cholesterol of $>3.2 \mathrm{mmol} / \mathrm{L}$, or use of lipid-lowering medication. Metabolic syndrome was determined by the National Cholesterol Education Program Expert Panel III criteria. ${ }^{16}$

\section{Markers of Extracranial Atherosclerosis}

An experienced technician performed carotid ultrasonography with a $10-\mathrm{MHz}$ linear-array transducer. Mean carotid intima-media thickness (cIMT) was calculated from 6 measurements (anterolateral, posterolateral, and mediolateral in both common carotid arteries). Extracranial carotid stenosis was ultrasonographically assessed and defined according to standard criteria based on the peak systolic velocity. ${ }^{17} \mathrm{ABI}$ measurements were conducted by experienced technicians and were calculated from the highest systolic blood pressure measured at the posterior tibial and dorsal pedal arteries by Doppler sonography and at both brachial arteries by a semiautomatic oscillometric device with the patient in the supine position. Renal function was assessed using the estimated glomerular filtration rate (eGFR) calculated by the Cockcroft-Gault equation adjusted for body weight and body mass index. ${ }^{18}$

Coronary artery disease was defined as a history of myocardial infarction or a history of coronary artery bypass graft surgery or percutaneous transluminal coronary angioplasty at inclusion or in the past. Cerebrovascular disease was defined as transient ischemic attack or stroke at inclusion or in the past. Peripheral artery disease was defined as intermittent claudication or rest pain at inclusion or a history of surgery or angioplasty of the arteries supplying the lower extremities. Abdominal aortic aneurysm was defined as the presence of an abdominal aortic aneurysm (distal aortic anteroposterior diameter of $\geq 3 \mathrm{~cm}$ ) or a previous abdominal aortic aneurysm operation. Multivascular disease was defined as the presence of $\geq 2$ of the above-defined vascular diseases.

\section{T MR Imaging Protocol}

A 7T whole-body system (Philips Healthcare, Best, the Netherlands) was used with a volume/transmit coil for transmission and a 32-channel receive head coil (Nova Medical, Wilmington, Massachusetts). Vessel wall MR imaging was performed using a T1-weighted magnetization-prepared inversion recovery TSE sequence, with the following parameters: FOV = 
$250 \times 250 \times 190 \mathrm{~mm}^{3}$, acquired resolution $=0.8 \times 0.8 \times$ $0.8 \mathrm{~mm}^{3}$ (reconstructed to $0.49 \times 0.49 \times 0.4 \mathrm{~mm}^{3}$ ), TR/TI/TE $=$ $3952 / 1375 / 37 \mathrm{~ms}$, acquisition time $=10$ minutes 40 seconds. ${ }^{19}$ In addition, an SWI sequence was performed, with the following parameters: $\mathrm{FOV}=200 \times 200 \times 120 \mathrm{~mm}^{3}$, acquired resolution $=$ $0.5 \times 0.5 \times 0.7 \mathrm{~mm}^{3}$ (reconstructed to $0.4 \times 0.4 \times 0.35 \mathrm{~mm}^{3}$ ), TR/ TE $1 /$ TE $2=20 / 6.9 / 15.8 \mathrm{~ms}$, flip angle $=12^{\circ}$, acquisition time $=$ 9 minutes 17 seconds.

\section{Assessment of Intracranial Atherosclerosis}

For the assessment of vessel wall lesions, axial multiplanar reconstructions were calculated from the T1-weighted magnetizationprepared inversion recovery TSE sequence (section thickness = $0.8 \mathrm{~mm}$; no section gap), angulated to the nasion-foramen magnum line. One observer (M.H.T.Z. with over 5 years of experience in neuroradiology) assessed all images, blinded to patient characteristics. M.H.T.Z. was trained by a senior observer with 8 years of experience in interpreting vessel wall MR images (A.G.v.d.K.), using a practice set of 15 patients from the intracranial vessel wall imaging (IVI) study ${ }^{20}$ and a consensus set of 20 patients from the current study. An interobserver agreement of 0.75 (Dice similarity coefficient) was obtained, which was regarded as good.

Vessel wall lesions were rated according to the methodology previously published by Lindenholz et al. ${ }^{21}$ A lesion was defined as either a focal or more diffuse thickening of the arterial wall of $>50 \%$, assessed visually, using the normal contralateral or neighboring arterial wall as a reference. Uncertain lesions were verified in multiple planes. After a lesion was identified, it was subsequently classified as eccentric ( $\leq 50 \%$ wall circumference) or concentric $(>50 \%$ wall circumference) and by arterial segment location: internal carotid arteries (C6, C7), middle cerebral arteries (M1, M2), anterior cerebral arteries (A1, A2), posterior communicating arteries, posterior cerebral arteries (P1, P2, and P1-P2 bifurcation), basilar artery, and vertebral arteries (V4). One single segment could contain multiple lesions, making the total lesion count theoretically unlimited. Lesions that extended into multiple segments were counted as separate lesions for each involved segment. Furthermore, lesions with eccentric and concentric components were regarded as separate lesions.

A maximum intensity projection of the SWI was used to assess the course of smaller arteries (M2, A1, P2, posterior communicating artery). We did not assess luminal stenosis because the SWI quality in our study did not permit accurate measurement, especially of small lesions. Of note, we did not perform a refined MRA because it was logistically not feasible, and at the time of study design, the diagnostic accuracy of MRA in the detection and grading of intracranial stenosis was still relatively low. ${ }^{22}$

\section{Statistical Analysis}

First, characteristics of the study sample were described. Next, the association of ECAS markers with ICAS burden was estimated using linear regression analyses, with the ECAS measure as the independent variable and ICAS burden as the dependent variable. ICAS burden was defined as the total number of intracranial vessel wall lesions. All analyses were adjusted for age and sex. ECAS measures were entered into the model as continuous and/or dichotomous variables. ABI was dichotomized by the
Table 1: Markers of extracranial atherosclerosis $(\mathrm{N}=130)^{\mathrm{a}}$

\begin{tabular}{lc}
\hline \multicolumn{1}{c}{ Markers } & \\
\hline Age (yr) & $68 \pm 9$ \\
Male & $88 \%$ \\
Carotid IMT (mm) & $0.84 \pm 0.22$ \\
Carotid stenosis $^{b}$ & \\
No stenosis & $23 \%$ \\
$1 \%-49 \%$ stenosis & $70 \%$ \\
$50 \%-100 \%$ stenosis & \\
Ankle-brachial index & $7 \%$ \\
ABI & \\
ABI $\leq 0.9$ & $1.09 \pm 0.18$ \\
Renal function & $11 \%$ \\
eGFR (mL/min) & \\
eGFR $<60$ mL/min & $72.8 \pm 17.3$ \\
History of vascular disease ${ }^{d}$ & $21 \%$ \\
Cerebrovascular disease & \\
Coronary artery disease & $9 \%$ \\
Peripheral artery disease & $65 \%$ \\
Multivascular disease & $9 \%$ \\
\hline
\end{tabular}

Note:-IMT indicates intima-media thickness.

${ }^{a}$ Values are presented as mean \pm SD for continuous variables and percentages for categorical variables.

${ }^{b}$ Categories are mutually exclusive. Patients were categorized according to most severe stenosis grade.

c Includes 4 patients with $\geq 1$ carotid artery occlusion.

${ }^{d}$ Categories are mutually exclusive. The multivascular category consisted of 22 patients with a history of $\geq 2$ vascular diseases: Ninety-five percent had coronary artery disease; $60 \%$, cerebrovascular disease; $60 \%$, peripheral artery disease; and $14 \%$, abdominal aortic aneurysm.

clinical cutoff for peripheral artery disease $(\leq 0.9) .{ }^{23}$ For eGFR, the clinical threshold for chronic kidney disease $(<60 \mathrm{~mL} / \mathrm{min})$ was used. cIMT was categorized into quartiles. Categorization of carotid stenosis was based on the most severe lesion in the bilateral extracranial common or internal carotid arteries. In the analyses of vascular disease, patients with $\geq 2$ vascular diseases were categorized as having multivascular disease, making categories mutually exclusive. Patients with only coronary artery disease were used as the reference category. A sensitivity analysis was performed to control for the time interval (in days) between the date of ECAS measurements and date of the 7T MR imaging.

Statistical analyses were performed using SPSS, Version 25.0 for Windows (IBM, Armonk, New York).

\section{RESULTS}

Table 1 shows the characteristics of the 130 patients. Eighty-eight percent were men, and the mean age was $68 \pm 9$ years. Twentyfive percent had multivascular disease. Although $19 \%$ of the population had cerebrovascular disease, in just 9\% was it the only disease. A majority of $65 \%$ had a sole history of coronary artery disease. An overview of vascular risk factors can be found in Online Table 1 . Of the 130 patients, $96 \%$ had $\geq 1$ intracranial vessel wall lesion and a mean ICAS burden of $8.5 \pm 5.7$ lesions (median, 7 lesions; range, 0-32 lesions). Furthermore, in the anterior circulation, a mean ICAS burden of $5.3 \pm 3.2$ lesions (median, 4 lesions; range, $0-14$ lesions) was found, which was $3.8 \pm 3.0$ lesions (median, 3 lesions; range, $0-18$ lesions) for the posterior circulation. More details regarding arterial or segmental distribution can be found in our prior publication. ${ }^{12}$ Examples of vessel wall lesions in a 76-year-old male patient are shown in the Figure. 


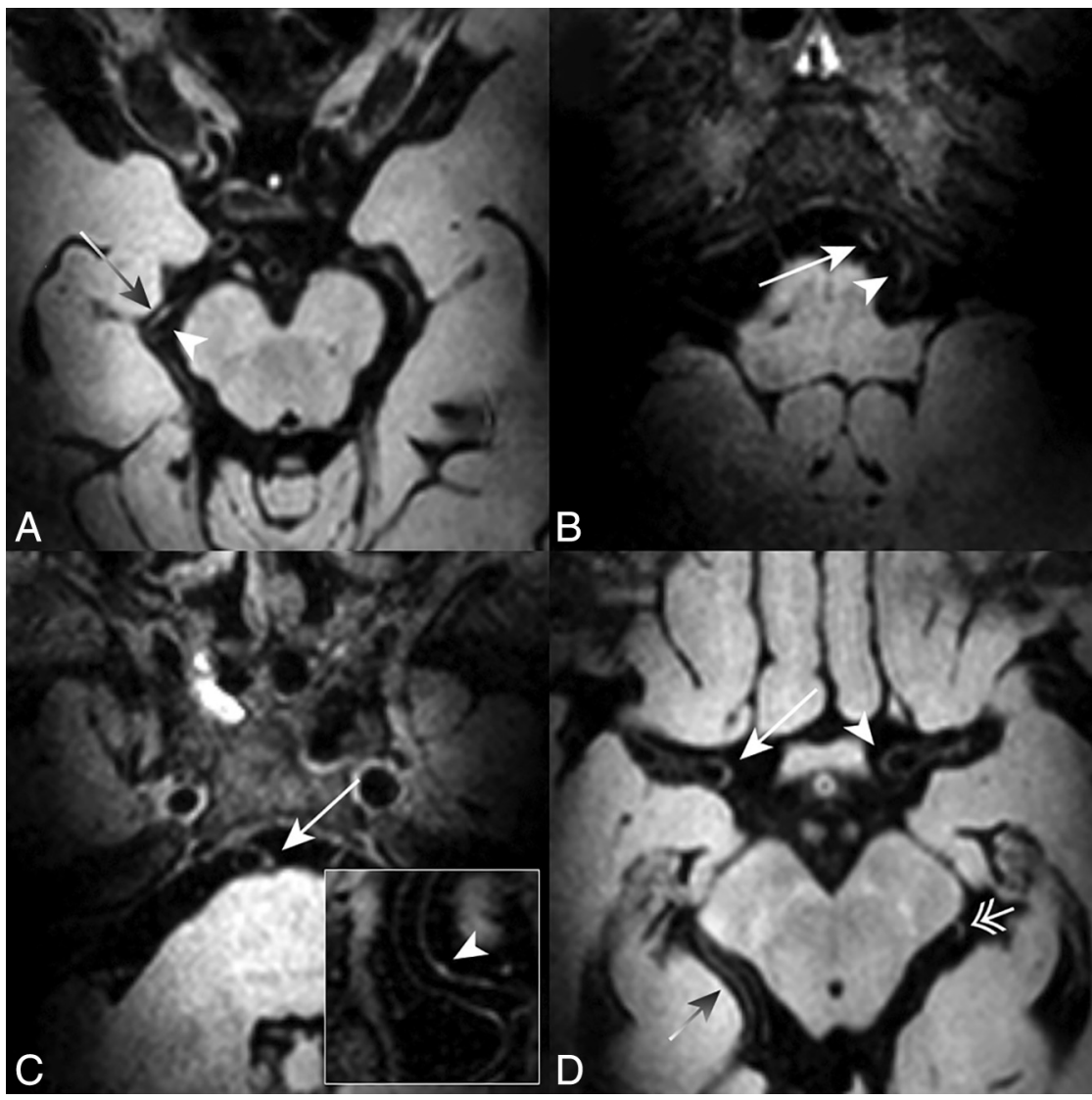

FIGURE. Examples of intracranial vessel wall lesions on vessel wall MR imaging in a 76-year-old male patient with a history of coronary artery disease. A detailed description of the rating criteria can be found in the Materials and Methods section. A, Lesion in lateral wall of the right P2 segment (arrow) versus the nondiscernable normal neighboring medial wall (arrowhead). B, Lesion in the right vertebral (arrow) and left vertebral (arrowhead) arteries. C, Lesion in the proximal basilar artery (arrow), with coronal orientation shown in enclosed panel (arrowhead). D, Lesion in the C7 segment of the right ICA (arrow), compared with the normal-appearing contralateral C7 segment (arrowhead) and proximal right M1 segment. Furthermore, note the long lesion in the distal half of the right P2 segment (gray arrow) and focal lesion in the left P2 segment (dual arrow).

Table 2: Association between carotid atherosclerosis and ICAS burden

\begin{tabular}{lc}
\hline & ICAS Burden $(b \text {-value })^{\mathrm{a}}(\mathbf{9 5 \%} \mathrm{Cl})$ \\
\hline cIMT, per $+0.1 \mathrm{~mm}$ & $0.53(0.06-0.98)$ \\
cIMT quartiles & 0 (Reference) \\
Quartile 1 & $0.62(-2.31-3.55)$ \\
Quartile 2 & $0.40(-2.61-3.41)$ \\
Quartile 3 & $2.89(-0.01-5.80)$ \\
Quartile 4 & \\
Carotid stenosis & 0 (Reference) \\
No stenosis & $2.48(0.08-4.89)$ \\
$1 \%-49 \%$ stenosis & $6.62(2.34-10.93)$ \\
$50 \%-100 \%$ stenosis & \\
\hline
\end{tabular}

${ }^{a} B$-values are unstandardized linear regression coefficients adjusted for age and sex.

Age- and sex-adjusted linear regression analyses showed that cIMT was significantly associated with a higher ICAS burden ( $b=0.53$ lesions per $+0.1 \mathrm{~mm}$; 95\% CI, 0.06-0.98 lesions). Analysis of cIMT in quartiles indicated a threshold effect, with only quartile 4 suggesting an association with ICAS burden.
However, because the $95 \%$ confidence interval contained 0.00 , it was not statistically significant (Table 2).

Carotid stenosis of $1 \%-49 \%$ was found to be associated with a higher ICAS burden compared with no carotid stenosis $(b=2.5$ lesions for presence of $1 \%-49 \%$ carotid stenosis; 95\% CI, 0.08-4.89 lesions). Carotid stenosis of $50 \%-100 \%$ was also associated with a higher ICAS burden $(b=$ 6.6 lesions for the presence of 50\%$100 \%$ carotid stenosis; 95\% CI, 2.3410.93 lesions) (Table 2).

$\mathrm{ABI}$ did not show a significant association with ICAS burden when analyzed as a continuous variable. However, when dichotomized by 0.9 , the clinical threshold for peripheral artery disease, a significant association with a higher ICAS burden was found, compared with $\mathrm{ABI}>0.9$ ( $b=4.9$ lesions for the presence of $\mathrm{ABI} \leq 0.9 ; 95 \% \mathrm{CI}, 1.74-7.99$ lesions) (Table 3 ).

eGFR was significantly associated with ICAS burden when analyzed as a continuous variable $(b=-0.77$ lesions per $+10 \mathrm{~mL} / \mathrm{min}$; $95 \% \mathrm{CI}$, -1.50 to -0.03 lesions). Furthermore, renal dysfunction (eGFR of $<60 \mathrm{~mL}$ / min) was also associated with a higher ICAS burden, compared with eGFR of $\geq 60 \mathrm{~mL} / \mathrm{min}$ ( $b=3.2$ lesions; 95\% CI, 0.45-5.91 lesions) (Table 4).

No significant differences in ICAS burden were observed among cerebrovascular, peripheral artery, or multivascular disease groups compared with only coronary heart disease (Table 5).

As a sensitivity analysis, all models were additionally adjusted for the time interval between the date of ECAS measurement and date of 7T MR imaging. On-line Tables 2-5 show the results of these analyses. Although the estimates slightly differed compared with the estimates without time interval adjustment, this did not lead to a change in statistical significance.

\section{DISCUSSION}

This study examined the association between the ICAS measured with intracranial vessel wall MR imaging at $7 \mathrm{~T}$ and several markers of ECAS, in a cohort of patients with a history of vascular disease. Our results show that increasing CIMT, the presence of extracranial carotid stenosis, $\mathrm{ABI} \leq 0.9$, and decreasing eGFR were all associated with a higher ICAS burden, defined as the number of intracranial vessel wall lesions. No differences in ICAS burden were observed between the presence of peripheral, cerebrovascular, or multivascular disease compared with coronary heart disease, the main disease in our population. 
Table 3: Association between ABI and ICAS burden

\begin{tabular}{lc}
\hline & ICAS Burden $(b \text {-value })^{\text {a }}(95 \% \mathrm{CI})$ \\
\hline $\mathrm{ABI}$, per +0.1 in ratio & $-0.36(-0.91-0.19)$ \\
$\mathrm{ABI}>0.9$ & 0 (Reference) \\
$\mathrm{ABI} \leq 0.9$ & $4.86(1.74-7.99)$ \\
\hline
\end{tabular}

${ }^{\mathrm{a}} B$-values are unstandardized linear regression coefficients adjusted for age and sex

Table 4: Association between renal function and ICAS burden

\begin{tabular}{lc}
\hline & ICAS Burden $(b \text {-value })^{\text {a }}(95 \% \mathrm{CI})$ \\
\hline eGFR, per $+10 \mathrm{~mL} / \mathrm{min}$ & $-0.77(-1.50$ to -0.03$)$ \\
eGFR $\geq 60 \mathrm{~mL} / \mathrm{min}$ & 0 (Reference) \\
eGFR $<60 \mathrm{~mL} / \mathrm{min}$ & $3.18(0.45-5.91)$ \\
\hline${ }^{a} B$-values are unstandardized linear regression coefficients adjusted for age and \\
sex.
\end{tabular}

Table 5: Association between history of vascular disease and ICAS burden

\begin{tabular}{lc}
\hline & ICAS Burden $(b \text {-value })^{\mathrm{a}}(\mathbf{9 5 \%} \mathrm{CI})$ \\
\hline Coronary artery disease & 0 (Reference) \\
Peripheral artery disease & $-0.22(-3.99-3.55)$ \\
Cerebrovascular disease & $0.01(-3.46-3.48)$ \\
Multivascular disease & $2.08(-0.60-4.76)$ \\
\hline
\end{tabular}

${ }^{a} B$-values are unstandardized linear regression coefficients adjusted for age and sex. Categories are mutually exclusive.

Cerebral arteries are thought to have a different response to vascular risk factors than extracranial arteries, and the relationship between ECAS and ICAS may therefore be relatively weak or absent. ${ }^{8,24,25}$ However, studies investigating this hypothesis in vivo have been based on the detection of arterial calcification or hemodynamically significant stenosis, both related to a more advanced stage of atherosclerotic disease. Furthermore, the heterogeneous etiology of arterial calcification and localization restricted to the proximal cerebral arteries might obscure detection of an association. Vessel wall MR imaging directly visualizes the pathologic vessel wall, enabling more accurate measurement of the ICAS burden. ${ }^{11,12,26}$

A very high frequency of ICAS was found in the current population, ${ }^{12}$ especially compared with other neuroimaging studies. This is in line with early postmortem studies that reported frequencies approaching $100 \%$ in older age. ${ }^{27,28}$ Furthermore, the distribution of vessel wall lesions, which we recently reported, ${ }^{12}$ was also in line with the distribution of plaques in those postmortem studies, particularly the increased involvement of the larger cerebral arteries compared with the smaller ones. These findings suggest that vessel wall MR imaging at $7 \mathrm{~T}$ allows a more accurate approximation of the ICAS burden, compared with other neuroimaging methods. However, more studies in different populations regarding age, sex, and disease status are needed to confirm this finding.

cIMT is an established marker of generalized atherosclerosis, ${ }^{29}$ though studies on its association with ICAS are limited. Our results are in line with a postmortem study, which reported an association of cIMT with the intima-media ratio of the cerebral vasculature. $^{30}$ Furthermore, a longitudinal study in patients with intracranial stenosis found that patients with progressive stenosis on MRA had a larger cIMT compared with those without progression, though this difference was not statistically significant. ${ }^{31}$

Extracranial carotid disease and ICAS are often assessed separately, likely because their prevalence varies among different ethnic populations. ${ }^{32}$ Notably, ICAS is thought to be most prevalent in populations of African and Asian descent, where it is a major cause of ischemic stroke, whereas in whites, it was thought to be less prevalent and a minor cause of ischemic stroke. However, recent studies have shown that the prevalence and importance of ICAS in whites may have been underestimated. ${ }^{12,33,34}$ Our results show a strong association between extracranial carotid stenosis and ICAS, a finding that is in concordance with a recent Asian study. ${ }^{35}$ Hence, our findings question the current segregation and suggest that they should not be assessed separately.

Low ABI has been associated with hemodynamically significant intracranial stenosis in community-based and ischemic stroke cohorts. ${ }^{36-38}$ Our results are in line with these findings and also show that a low ABI is associated with the more continuous spectrum of disease measured by ICAS burden, not just hemodynamic stenosis.

Renal dysfunction is an independent risk factor for cardiovascular disease $^{39}$ and has been linked to ischemic stroke, cerebral small vessel disease, and medial arterial calcification. ${ }^{40,41}$ A recent scientific abstract reported an association between renal dysfunction and intracranial arterial wall thickening, which is in concordance with our results. ${ }^{42}$

No significant differences in ICAS burden were observed in patients with a history of cerebrovascular, peripheral artery, or multivascular disease compared with coronary heart disease. An association with cerebrovascular disease might have been expected because ICAS is a major cause of ischemic stroke. ${ }^{1}$ In our prior study, we did find an association between ICAS burden and the presence of ischemic infarcts. ${ }^{12}$ However, in the current analyses, the outcome was clinical stroke and/or TIA, which is an overlapping-but-different entity. Furthermore, small sample sizes of all categories, except for coronary heart disease, may also have prevented observation of significant relationships. Notably, earlier studies from our group in patients with acute ischemic stroke and controls also did not find an association between the number of vessel wall lesions and ischemic stroke. ${ }^{43}$

A main strength of this study is the use of vessel wall MR imaging at 7T, one of the most accurate methods to assess intracranial atherosclerosis in vivo, which enabled visualization of atherosclerosis beyond stenosis. Furthermore, it provided a large coverage area, which allowed assessment of the circle of Willis' branches over a great length. Moreover, the increased contrastto-noise ratio facilitated a more reliable identification of lesions than is possible at lower field strengths. A last strength is the various measures of ECAS, which allowed an integrated assessment of multiple arterial beds in the same patient.

Several limitations also need to be addressed. First, there is a paucity of radiopathologic studies on vessel wall lesions, making it possible that not all lesions are atherosclerotic. Second, our sample size, though large compared with previous 7T studies, is still relatively small compared with other epidemiologic studies. Third, our cohort consisted of patients with a history of vascular disease with most being men, which may limit generalization of 
our results to other populations. Fourth, we used a basic uniparametric score to quantify ICAS burden, which does not account for other quantitative features, such as wall thickness. However, accurate quantitative assessment of lesions, especially the very small lesions visible at $7 \mathrm{~T}$, is limited at current spatial resolutions. ${ }^{44}$ As a result, grading lesions is a qualitative process and inherently less objective than quantitative grading. Nonetheless, increased objectivity can be obtained by training, experience, and attaining good reproducibility compared with senior observers, as in the current study. Furthermore, we did not assess luminal stenosis because we did not include a refined MRA in the protocol. As advancements to current vessel wall sequences are starting to enable more accurate measurements, development of multiparametric scoring systems (eg, the Gensini score for coronary artery disease), taking into account lesion location, stenosis grade, different geometric characteristics (eg, remodeling index), signal intensity on various weightings, and contrast-enhanced MR imaging, may enable a more versatile way to study the relation among ICAS, ECAS, and clinical outcomes. Last, due to logistic reasons, the ECAS assessment and the 7T MR imaging were not performed on the same day, and in a number of participants, the time interval was quite large. Because ECAS markers could have changed during this interval, this feature may have influenced the observed associations. However, most estimates differed only slightly and did not lead to different conclusions.

\section{CONCLUSIONS}

In patients with a history of various manifestations of vascular disease, ICAS burden, defined as the number of intracranial vessel wall lesions, was associated with atherosclerotic disease in all extracranial arterial beds, not supporting a different etiology. Our results may be used to further elucidate the etiology of ICAS and may be of interest to clinical studies looking for effective ways to select patients at risk of ICAS.

\section{ACKNOWLEDGMENTS}

Members of the Utrecht Cardiovascular Cohort-Second Manifestations of ARTerial disease Study Group (UCC-SMART Study Group): F.W. Asselbergs and H.M. Nathoe, Department of Cardiology; G.J. de Borst, Department of Vascular Surgery; M.L. Bots and M.I. Geerlings, Julius Center for Health Sciences and Primary Care; M.H. Emmelot, Department of Geriatrics; P.A. de Jong and T. Leiner, Department of Radiology; A.T. Lely, Department of Obstetrics and Gynecology; N.P. van der Kaaij, Department of Cardiothoracic Surgery; L.J. Kappelle and Y.M. Ruigrok, Department of Neurology; M.C. Verhaar, Department of Nephrology; F.L.J. Visseren (Chair) and J. Westerink, Department of Vascular Medicine, University Medical Center Utrecht and Utrecht University.

\section{REFERENCES}

1. Qureshi AI, Caplan LR. Intracranial atherosclerosis. Lancet 2014;383:984-98 CrossRef Medline

2. Dearborn JL, Zhang Y, Qiao Y, et al. Intracranial atherosclerosis and dementia. Neurology 2017;88:1556-63 CrossRef Medline
3. Gorelick P, Wong KS, Liu L. Epidemiology. Front Neurol Neurosci 2016;40:34-46 CrossRef Medline

4. Qiao Y, Suri FK, Zhang Y, et al. Racial differences in prevalence and risk for intracranial atherosclerosis in a US community-based population. JAMA Cardiol 2017;2:1341-48 CrossRef Medline

5. Sternby NH. Atherosclerosis in a defined population: an autopsy survey in Malmö, Sweden. Acta Pathol Microbiol Scand 1968:Suppl 194:5+ Medline

6. D'Armiento FP, Bianchi A, de Nigris F, et al. Age-related effects on atherogenesis and scavenger enzymes of intracranial and extracranial arteries in men without classic risk factors for atherosclerosis. Stroke 2001;32:2472-79 CrossRef Medline

7. Kiechl S, Willeit J. The natural course of atherosclerosis, Part I: incidence and progression. Arter Thromb Vasc Biol 1999;19:1484-90 CrossRef Medline

8. Ritz K, Denswil NP, Stam O, et al. Cause and mechanisms of intracranial atherosclerosis. Circulation 2014;130:1407-14 CrossRef Medline

9. Suri MF, Qiao Y, Ma X, et al. Prevalence of intracranial atherosclerotic stenosis using high-resolution magnetic resonance angiography in the general population: the Atherosclerosis Risk in Communities study. Stroke 2016;47:1187-93 CrossRef Medline

10. López-Cancio E, Dorado L, Millán M, et al. The BarcelonaAsymptomatic Intracranial Atherosclerosis (AsIA) study: prevalence and risk factors. Atherosclerosis 2012;221:221-25 CrossRef Medline

11. Qiao Y, Anwar Z, Intrapiromkul J, et al. Patterns and implications of intracranial arterial remodeling in stroke patients. Stroke 2016;47:434-40 CrossRef Medline

12. Zwartbol MHT, van der Kolk AG, Ghaznawi R, et al. Intracranial vessel wall lesions on 7T MRI. Stroke 2019;50:88-94 CrossRef Medline

13. Bhogal $P$, Navaei $E$, Makalanda $H L$, et al. Intracranial vessel wall MRI. Clin Radiol 2016;71:293-303 CrossRef Medline

14. Harteveld AA, van der Kolk AG, van der Worp HB, et al. High-resolution intracranial vessel wall MRI in an elderly asymptomatic population: comparison of 3T and 7T. Eur Radiol 2017;27:1585-95 CrossRef Medline

15. Geerlings MI, Appelman AP, Vincken KL, et al. Brain volumes and cerebrovascular lesions on MRI in patients with atherosclerotic disease: the SMART-MR study. Atherosclerosis 2010;210:130-36 CrossRef Medline

16. National Cholesterol Education Program (NCEP) Expert Panel on Detection, Evaluation, and Treatment of High Blood Cholesterol in Adults (Adult Treatment Panel III). Third Report of the National Cholesterol Education Program (NCEP) Expert Panel on Detection, Evaluation, and Treatment of High Blood Cholesterol in Adults (Adult Treatment Panel III) final report. Circulation 2002;106:3143421 Medline

17. Simons PC, Algra A, Van De Laak MF, et al. Second manifestations of ARTerial disease (SMART) study: rationale and design. Eur J Epidemiol 1999;15:773-81 CrossRef Medline

18. Winter MA, Guhr KN, Berg GM. Impact of various body weights and serum creatinine concentrations on the bias and accuracy of the Cockcroft-Gault Equation. Pharmacother J Hum Pharmacol Drug Ther 2012;32:604-12 CrossRef Medline

19. van der Kolk AG, Hendrikse J, Brundel M, et al. Multi-sequence whole-brain intracranial vessel wall imaging at 7.0 Tesla. Eur Radiol 2013;23:2996-3004 CrossRef Medline

20. van der Kolk AG, Zwanenburg JJ, Brundel M, et al. Distribution and natural course of intracranial vessel wall lesions in patients with ischemic stroke or TIA at 7.0 Tesla MRI. Eur Radiol 2015;25:1692700 CrossRef Medline

21. Lindenholz A, van der Kolk AG, Zwanenburg JJ, et al. The use and pitfalls of intracranial vessel wall imaging: how we do it. Radiology 2018;286:12-28 CrossRef Medline 
22. Holmstedt CA, Turan TN, Chimowitz MI. Atherosclerotic intracranial arterial stenosis: risk factors, diagnosis, and treatment. Lancet Neurol 2013;12:1106-14 CrossRef Medline

23. Aboyans V, Criqui MH, Abraham $\mathrm{P}$, et al. Measurement and interpretation of the Ankle-Brachial Index: a scientific statement from the American Heart Association. Circulation 2012;126:2890-909 CrossRef Medline

24. López-Cancio E, Galán A, Dorado L, et al. Biological signatures of asymptomatic extra- and intracranial atherosclerosis: the Barcelona-AsIA (Asymptomatic Intracranial Atherosclerosis) study. Stroke 2012;43:2712-19 CrossRef Medline

25. Odink AE, van der Lugt A, Hofman A, et al. Association between calcification in the coronary arteries, aortic arch and carotid arteries: the Rotterdam study. Atherosclerosis 2007;193:408-13 CrossRef Medline

26. Mandell DM, Mossa-Basha M, Qiao Y, et al. Intracranial Vessel Wall MRI: Principles and Expert Consensus Recommendations of the American Society of Neuroradiology. AJNR Am J Neuroradiol 2017;38:218-29 CrossRef Medline

27. Resch JA, Baker AB. Etiologic mechanisms in cerebral atherosclerosis: preliminary study of $3, \mathbf{8 3 9}$ cases. Arch Neurol 1964;10:617-28 CrossRef Medline

28. Mathur KS, Kashyap SK, Kumar V. Correlation of the extent and severity of atherosclerosis in the coronary and cerebral arteries. Circulation 1963;27:929-34 CrossRef Medline

29. Bots ML, Sutton-Tyrrell K. Lessons from the past and promises for the future for carotid intima-media thickness. J Am Coll Cardiol 2012;60:1599-604 CrossRef Medline

30. Iwakiri T, Yano Y, Sato Y, et al. Usefulness of carotid intima-media thickness measurement as an indicator of generalized atherosclerosis: findings from autopsy analysis. Atherosclerosis 2012;225:35962 CrossRef Medline

31. Mizukami H, Shimizu T, Maki F, et al. Progression of intracranial major artery stenosis is associated with baseline carotid and intracranial atherosclerosis. J Atheroscler Thromb 2015;22:183-90 CrossRef Medline

32. Caplan LR, Gorelick PB, Hier DB. Race, sex and occlusive cerebrovascular disease: a review. Stroke 1986;17:648-55 CrossRef Medline
33. Bos D, van der Rijk MJ, Geeraedts TE, et al. Intracranial carotid artery atherosclerosis: prevalence and risk factors in the general population. Stroke 2012;43:1878-84 CrossRef Medline

34. Bos D, Portegies ML, van der Lugt A, et al. Intracranial carotid artery atherosclerosis and the risk of stroke in whites. JAMA Neurol 2014;71:405 CrossRef Medline

35. Man BL, Fu YP. Concurrent stenoses: a common etiology of stroke in Asians. World J Clin Cases 2014;2:201-05 CrossRef Medline

36. Manzano JJ, De Silva DA, Pascual JL, et al. Associations of anklebrachial index (ABI) with cerebral arterial disease and vascular events following ischemic stroke. Atherosclerosis 2012;223:219-22 CrossRef Medline

37. Nakano T, Ohkuma H, Suzuki S. Measurement of ankle brachial index for assessment of atherosclerosis in patients with stroke. Cerebrovasc Dis 2004;17:212-17 CrossRef Medline

38. Jiménez M, Dorado L, Hernández-Pérez M, et al. Ankle-brachial index in screening for asymptomatic carotid and intracranial atherosclerosis. Atherosclerosis 2014;233:72-75 CrossRef Medline

39. Manjunath $G$, Tighiouart $H$, Ibrahim $H$, et al. Level of kidney function as a risk factor for atherosclerotic cardiovascular outcomes in the community. J Am Coll Cardiol 2003;41:47-55 CrossRef Medline

40. Makin SD, Cook FA, Dennis MS, et al. Cerebral small vessel disease and renal function: systematic review and meta-analysis. Cerebrovasc Dis 2015;39:39-52 CrossRef Medline

41. Power A, Chan $\mathrm{K}, \mathrm{Haydar} \mathrm{A}$, et al. Intracranial arterial calcification is highly prevalent in hemodialysis patients but does not associate with acute ischemic stroke. Hemodial Int 2011;15:256-63 CrossRef Medline

42. Qing HA, Gottesman R, Qiao Y, et al. Abstract TMP52: Association of chronic kidney disease and intracranial atherosclerotic disease by high resolution vessel wall MRI: the ARIC study. Stroke 2018;49 (Suppl 1) CrossRef

43. Harteveld AA, van der Kolk AG, van der Worp HB, et al. Detecting intracranial vessel wall lesions with $7 \mathrm{~T}$-magnetic resonance imaging: patients with posterior circulation ischemia versus healthy controls. Stroke 2017;48:2601-04 CrossRef Medline

44. van Hespen KM, Zwanenburg JJ, Harteveld AA, et al. Intracranial vessel wall magnetic resonance imaging does not allow for accurate and precise wall thickness measurements. Stroke 2019;50:e283-84 CrossRef 